\title{
AN OBJECT-BASED WORKFLOW DEVELOPED TO EXTRACT AQUACULTURE PONDS FROM AIRBORNE LIDAR DATA: A TEST CASE IN CENTRAL VISAYAS, PHILIPPINES
}

\author{
R. A. Loberternos ${ }^{\mathrm{a},}$, W. P. Porpetcho ${ }^{\mathrm{a}}$, J. C. A. Graciosa ${ }^{\mathrm{a}}$, R. R. Violanda ${ }^{\mathrm{a}, \mathrm{b}}$, A. G. Diola ${ }^{\mathrm{a}, \mathrm{c}}$, D. T. Dy, , , R. E. S. Otadoy ${ }^{\mathrm{a}, \mathrm{b}}$ \\ ${ }^{a}$ USC Phil-LiDAR Research Center, Fr. Josef Baumgartner Learning Resource Center, University of San Carlos - \\ Talamban Campus, Nasipit, Talamban, 6000 Cebu City, Philippines - (b1.reagan, nipnip29, juancarlosgraciosa, renante.violanda, \\ usctcdream, dydt.up, rolandotadoy2012)@gmail.com \\ ${ }^{b}$ Theoretical and Computational Sciences and Engineering Group, Department of Physics, \\ University of San Carlos, 6000 Cebu City, Philippines \\ ${ }^{\mathrm{c}}$ Department of Biology, University of San Carlos, 6000 Cebu City, Philippines
}

KEY WORDS: Object-Based Image Analysis (OBIA), multiresolution segmentation, coastal land use, fishpond

\begin{abstract}
:
Traditional remote sensing approach for mapping aquaculture ponds typically involves the use of aerial photography and high resolution images. The current study demonstrates the use of object-based image processing and analyses of LiDAR-data-generated derivative images with 1-meter resolution, namely: CHM (canopy height model) layer, DSM (digital surface model) layer, DTM (digital terrain model) layer, Hillshade layer, Intensity layer, NumRet (number of returns) layer, and Slope layer. A Canny edge detection algorithm was also performed on the Hillshade layer in order to create a new image (Canny layer) with more defined edges. These derivative images were then used as input layers to perform a multi-resolution segmentation algorithm best fit to delineate the aquaculture ponds. In order to extract the aquaculture pond feature, three major classes were identified for classification, including land, vegetation and water. Classification was first performed by using assign class algorithm to classify Flat Surfaces to segments with mean Slope values of 10 or lower. Out of these Flat Surfaces, assign class algorithm was then performed to determine Water feature by using a threshold value of 63.5. The segments identified as Water were then merged together to form larger bodies of water which comprises the aquaculture ponds. The present study shows that LiDAR data coupled with object-based classification can be an effective approach for mapping coastal aquaculture ponds. The workflow currently presented can be used as a model to map other areas in the Philippines where aquaculture ponds exist.
\end{abstract}

\section{INTRODUCTION}

For more than half a century, remote sensing imagery has been acquired by a multitude of airborne and space-borne sensors having multispectral sensors with wavelengths ranging from visible to microwave, and with spatial resolutions ranging from sub-meter to kilometers (Navulur, 2006, Xie et al., 2008). The popular type of remotely sensed data for extraction of land cover features to date are either high-resolution (e.g., WorldView, Quickbird or IKONOS) or medium resolution (e.g. Landsat, ASTER or SAR) satellite imagery (Travaglia et al., 2004; Xie et al., 2008).

A recent technology for mapping land covers and water uses LiDAR (Light Detection and Ranging) system that is mounted on an aircraft. Current use of LiDAR data includes not only for safe marine navigation but also in support of a wide array of coastal science and management applications (Parrish et al., 2010; Travaglia, et al., 2004). The operation is more localized and the cost is also relatively cheaper.

In the past, remote sensing has been carried out in the past decades to monitor mangroves and its conversion to brackish water aquaculture ponds (Shi et al., 2009). It has been widely accepted that remote sensing plays an important role for producing fast, detailed and accurate coastal land cover and land use maps: an essential component for supporting ecological understanding, conservation management and in improving coastal regulation (Terchunian et al., 1986; Parrish et al., 2010). With advances in LiDAR technology, it is now possible to map terrestrial and coastal resources with precision and with increasing frequency in emerging economies such as the Philippines.

There have been numerous studies focused on identifying land covers using object-based analysis of LiDAR data (Navulur, 2006; Miliaresis, 2007). However, less focus has been done on extracting aquaculture pond features using object-based analysis.

This paper reports on a specific approach to a method for undertaking high resolution mapping of aquaculture ponds.

\section{METHODOLOGY}

\subsection{Study Area}

The coastal area of Carcar City in the province of Cebu was the subject of research in this study. Cebu is one of the four provinces in Central Visayas, Philippines. The length of the coastal area in Carcar City is about $16 \mathrm{~km}$.

\section{* Corresponding author}




\subsection{Data}

The data comprise a 3-band digital orthophotograph and LiDAR point cloud LAS file from Phil-LiDAR 2 Program "Nationwide Detailed Resources Assessment Using LiDAR." It is a national program funded by the Department of Science and Technology (DOST), Republic of the Philippines.

\subsection{Data Preparation}

Using LAStools software, LiDAR point cloud data were prepared for processing derivative layers such as CHM (canopy height model), DSM (digital surface model), DTM (digital terrain model), Intensity, Slope, Hillshade, and NumRet (number of returns). These layers are projected images (WGS 84 UTM Zone 51 projection) with a 1 meter-per-pixel resolution.

The generated LiDAR derivative layers are in tiles of $1 \mathrm{~km}$-by$1 \mathrm{~km}$ dimensions. Since the focus of this study is per coastal municipality, tiles that were adjacent to each other were then sorted out and merged to form larger layers. This was done by using the Mosaic to New Raster Tool in ArcGIS 10.2 with a minimum of 2 and maximum of 12 tiles per layer. The orthophotographs of the corresponding LiDAR derivative tiles were also sorted out and merged using the same procedure.

\subsection{Image Processing}

Segmentation and classification of the LiDAR derivative layers were performed using the Object-Based Image Analysis (OBIA) tools in the eCognition Developer 64 software version 9.0. As an added feature image layer, a Canny layer was generated by applying edge extraction canny (Canny's algorithm) on the Hillshade derivative layer (Canny, 2009). Automated classification was performed for the extraction of Land, Vegetation and Water features (See Fig. 1a).

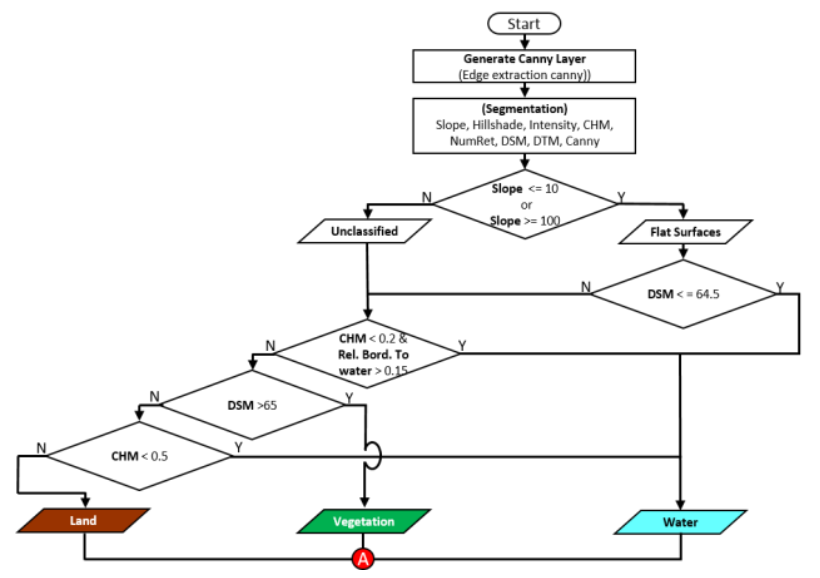

Figure 1a. Detailed workflow of Land, Vegetation and Water feature extraction.

The second phase of the workflow used manual classification for the refinement of the classified segments. However, another set of automated classification was performed for the extraction of the aquaculture ponds (see Fig. 1b).

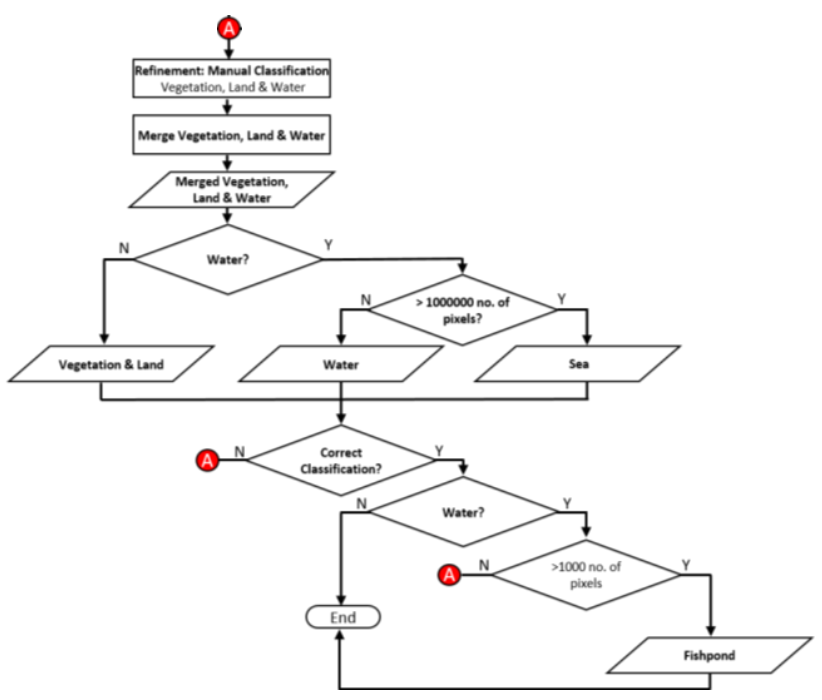

Figure 1b. Detailed workflow of Aquaculture ponds (fishpond) feature extraction.

\subsubsection{Segmentation}

In order to estimate the most appropriate combination of weights to be used for each LiDAR derivative layer when doing the multi-resolution segmentation algorithm, the said algorithm was first performed to each LiDAR derivative layer using uniform parameters. This was done in order to find which LiDAR derivative layers were able to delineate the boundary of aquaculture ponds (or fishponds in local dialect) from their neighbouring features (see Fig. 2).

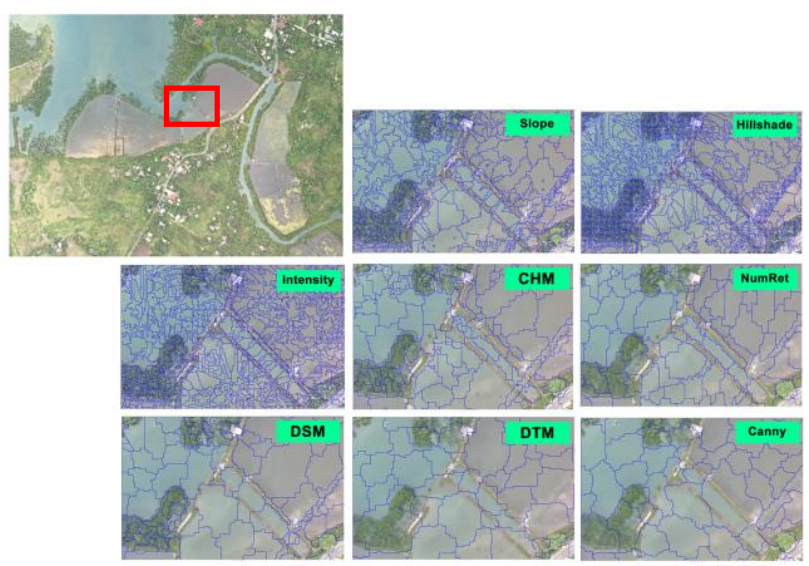

Figure 2. Segmentation results for each LiDAR derivative using default settings for multi-resolution segmentation algorithm in eCognition (scale parameter: 10; shape: 0.1; compactness: $0.5)$.

From purely visual inspections, the following weights were established: Slope (7), Hillshade (5), Intensity (3), CHM (2), NumRet (1), DSM (1), DTM (1), Canny (1) and Orthophotographs (1). It may be noteworthy to point out that the orthophotographs were given only the minimum weight, not for their effectiveness in terms of delineation but rather on the merits of their availability (since some LiDAR data lack corresponding orthophotographs). Using the above LiDAR derivative layers with their corresponding weights, a multiresolution segmentation algorithm was done (scale parameter: 20; shape: 0.3 ; compactness: 0.1 ). 


\subsubsection{Classification}

From the segmented objects, it was established that flat surfaces such as roads, wetlands, the sea, fishponds, and rice fields have mean slope values less than or equal to 10 . Hence, the value of 10 was used as a maximum threshold for the assign class algorithm to classify Flat Surfaces.

Fishponds surroundings are commonly vegetated. Majority of the surrounding vegetation have mean $\mathrm{CHM}$ values not lower than 1.5. Hence, the value of 1.5 was used as a maximum threshold for the assign class algorithm to classify Vegetation.

Most bodies of water have mean CHM values not more than 0.2 . However, built-up areas have negative mean CHM values. Using 0.2 as a maximum threshold to assign the remaining unclassified segments to Water would also mean that the said built-up will also be erroneously classified as Water. To avoid this, a second condition was made which is to limit such classifications to unclassified segments with relative borders to segments already classified as Water. With this algorithm, Flat Surfaces can also be included in the class filters. Furthermore, an intermediate step using mean DSM values was employed. A value of 65 was used as a maximum threshold for the assign class algorithm using mean DSM values to define the said unclassified segments as Vegetation. What remains now are the unclassified bodies of water or fields with mean $\mathrm{CHM}$ values less than 0.2. This value was then used as a maximum threshold to assign the remaining unclassified segments to Water.

The last step before the manual classification procedure was the conversion of all unclassified segments as well as the Flat Surfaces to Land class.

The neighbouring segments of the same class were then merged together to form larger segments. Bodies of water which were part of the sea will have the same Water feature classification as those on aquaculture ponds. To determine the segments classified as Water that are part of the aquaculture ponds, a filtering algorithm was performed to discard these segments by excluding Water features with pixel value more than $1,000,000$ pixels (most aquaculture pond areas were around $1,000,000$ pixels or less).

\subsection{Validation}

To confirm the accuracy of the classified aquaculture ponds, field validation was conducted. Ocular inspections were mostly limited only at the boundaries of the aquaculture ponds because most of the aquaculture ponds were privately owned. The validation points were further verified by visual inspection of the orthophotographs.

\section{RESULTS}

\subsection{Fishpond Feature Extraction}

In the first classification of Flat Surface, it was observed that segmented objects corresponding to water regions have mean slope values greater than 100 . Hence, the value of 100 was used as a maximum threshold value for a second assign class algorithm to classify Flat Surfaces, respectively (see Fig. 3).
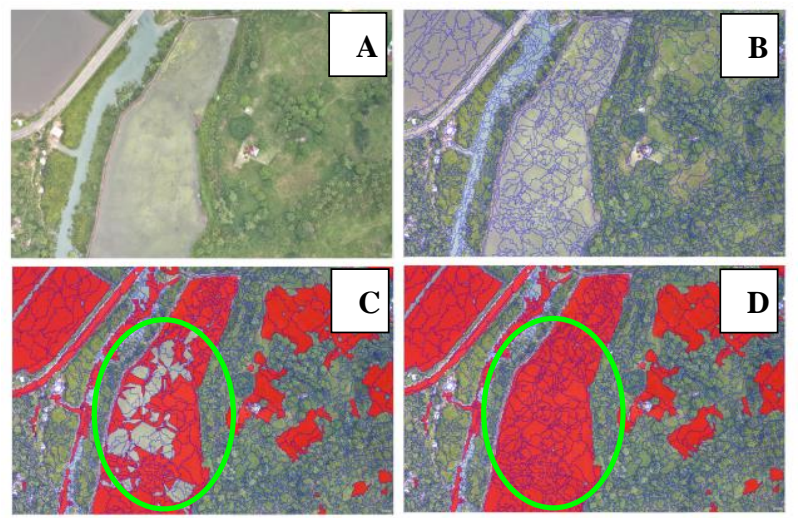

Figure 3. Orthophotographs before (A) and after (B) multiresolution segmentation. Flat Surfaces classification using assign class algorithm with mean Slope maximum and minimum threshold values of 10 (C) and then 100 (D).

The second classification made was from class Flat Surfaces. Using the assign class algorithm all Flat Surfaces that have Mean DSM values of 63.5 or lower were classified as Water (see Fig. 4).
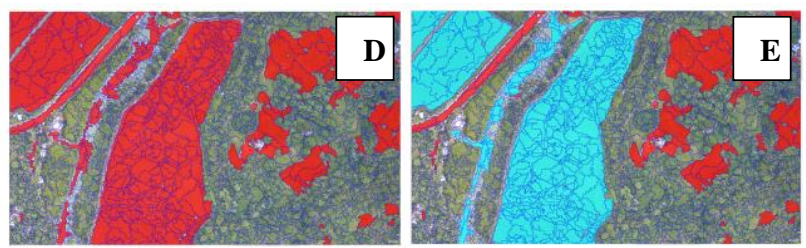

Figure 4. Flat Surfaces (D) to Water (E) object classification using assign class algorithm with mean DSM maximum threshold value of 63.5 .

One feature observed during image processing was how well the dikes defined the boundaries of the aquaculture ponds, which were mostly buffered with vegetation. Identifying the Vegetation feature around the aquaculture ponds significantly aided in defining their boundaries and dikes. Majority of these vegetation have mean CHM values not lower than 1.5. Hence, the value of 1.5 was used as a maximum threshold for the assign class algorithm to classify Vegetation (see Fig. 5).
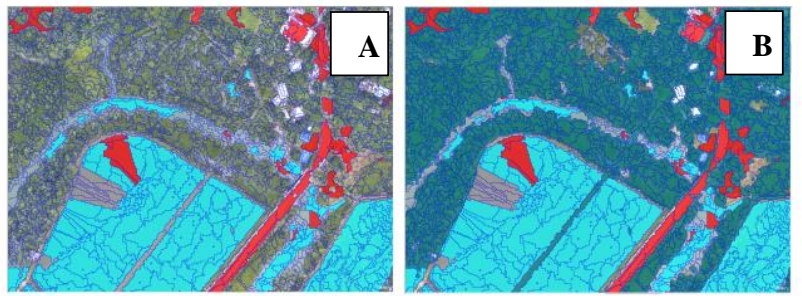

Figure 5. Segments before (A) and after (B) Vegetation classification using assign class algorithm with mean CHM minimum threshold value of 1.5 .

Looking back on the threshold values used to generate Flat Surfaces class, we can determine that segments with mean slope values of 10 to 100 were excluded. There were also segments that may be excluded from the classification of Vegetation since the minimum mean CHM threshold value used was 1.5. Most bodies of water have mean CHM values not more than 0.2. However, built-ups have negative mean CHM values. Using 0.2 as a maximum threshold to assign the remaining unclassified segments to Water would also mean that the said 
built-ups will also be erroneously classified as Water. To avoid this, a second condition must be made which is to limit such classifications to unclassified segments with relative borders to segments already classified as Water (see Fig. 6). With this algorithm, Flat Surfaces can also be included in the class filters.
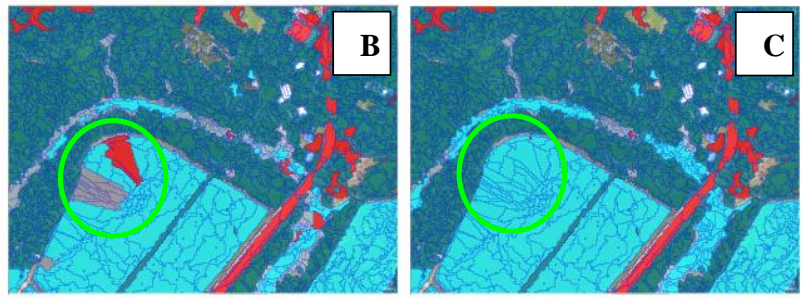

Figure 6. Water classification using assign class algorithm with mean CHM maximum threshold value of 0.2 and a 2 nd condition of relative border to Water of 0.15 .

Despite the previous step, there still remain unclassified segments at this point of the process which were Water feature upon cursory inspection in the orthophotographs (see Fig. 7C). These segments are those with no relative borders with segments already classified as Water. Most of these unclassified segments again have mean CHM values lesser than 0.2. However, as previously stated, built-ups such as houses have negative mean CHM values. So if we classify all the remaining unclassified segments as Water immediately, the said built-ups will be erroneously classified as Water because they also have CHM values lesser than 0.2 (see Fig. 7X).
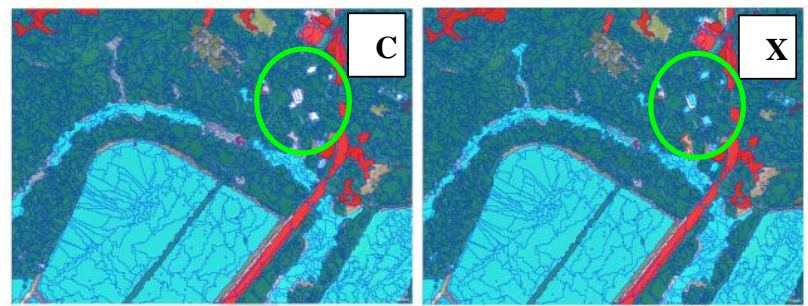

Figure 7. Water classification using assign class algorithm with mean CHM maximum threshold value of 0.2 .

To avoid this, an intermediate step using mean DSM values must be employed. A value of 65 was used as a maximum threshold for the assign class algorithm using mean DSM values to define the said unclassified segments as Vegetation (see Fig. 8 ). Note that this particular study only focused on the extraction of aquaculture ponds so it was only for reasons of simplification that the said built-ups were classified to Vegetation and not to an additional but unnecessary feature classification.
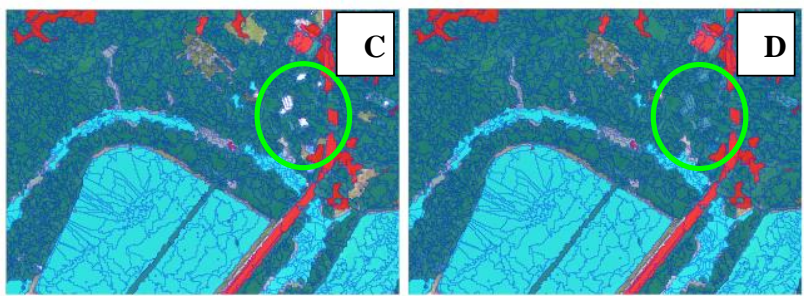

Figure 8. Vegetation classification using assign class algorithm with mean DSM minimum threshold value of 65 .

Using the mean CHM values less than 0.2 as a maximum threshold to assign the remaining unclassified segments to
Water precisely classified the previously unclassified bodies of water without including the built-ups (see Fig. 9).

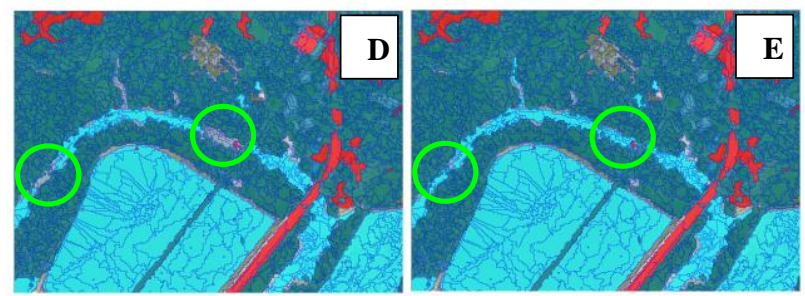

Figure 9. Water classification using assign class algorithm with mean CHM maximum threshold value of 0.2 .

The last step before the manual classification procedure was the conversion of all unclassified segments as well as the Flat Surfaces to Land class. With this step, there were only 3 classifications left for the segments namely Land, Vegetation, and Water (see Fig. 10).
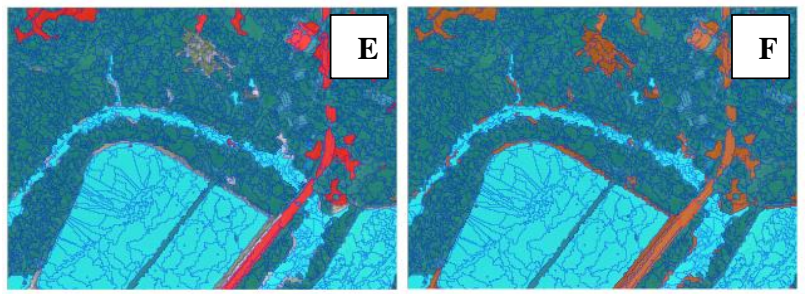

Figure 10. Classification using assign class algorithm converting all unclassified segments and Flat Surfaces class (E) to Land class $(\mathrm{F})$.

Bodies of water which were part of the sea have the same Water feature classification as those on aquaculture ponds (see Fig. 11a).

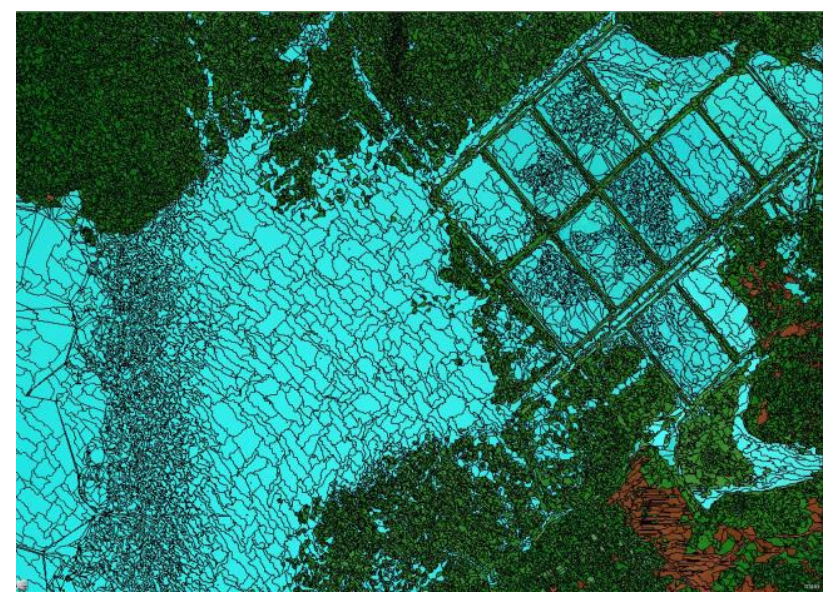

Figure 11a. Image showing segments classified as Water for both sea and aquaculture ponds.

Since the segments classified as Water were already identified, what was left was to separate the Water segments considered to be part of the aquaculture ponds. In order to do that, the neighbouring segments of the same class were then merged together to form larger segments of the same Water classification (see Fig. 11b). 


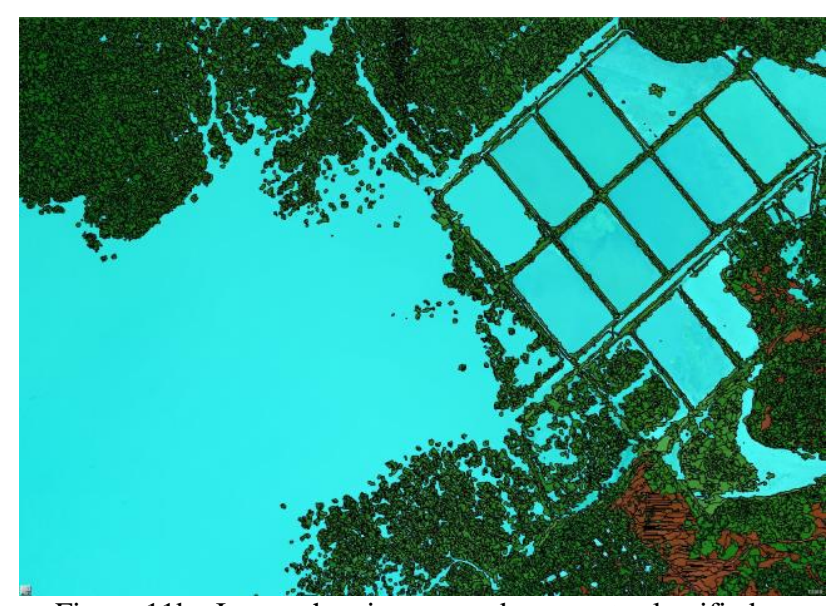

Figure 11b. Image showing merged segments classified as Water for both sea and aquaculture ponds.

This was done since Water segments greater than $1,000,000$ pixels represented the sea, hence classified as Sea (see Fig. 11c).

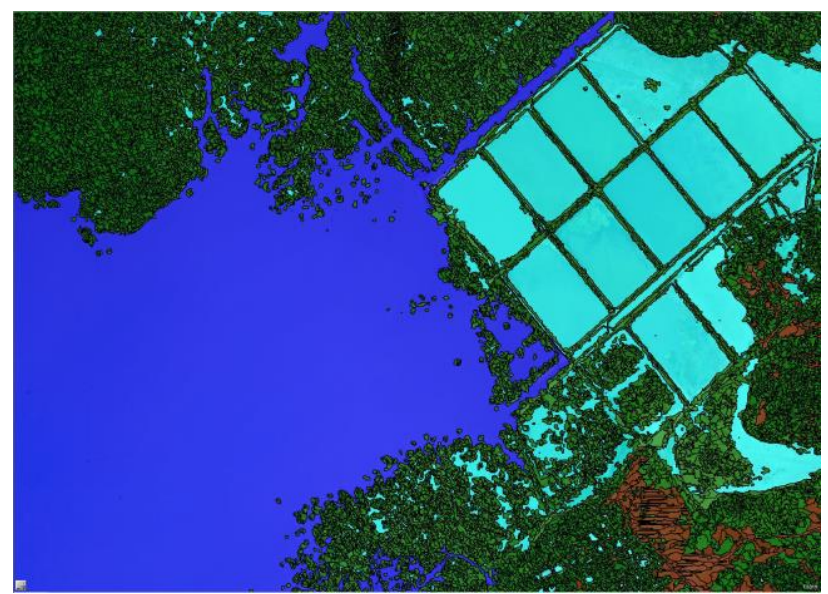

Figure 11c. Image showing extracting the sea.

Despite the extraction of sea, there were still Water segments which did not belong to the aquaculture ponds (see smaller Water segments of Fig. 11c). Water segments with number of pixels small than 20,000 were reclassified to Vegetation (see Fig. 11s), which left the remaining segments classified as Water to be those of the aquaculture ponds.

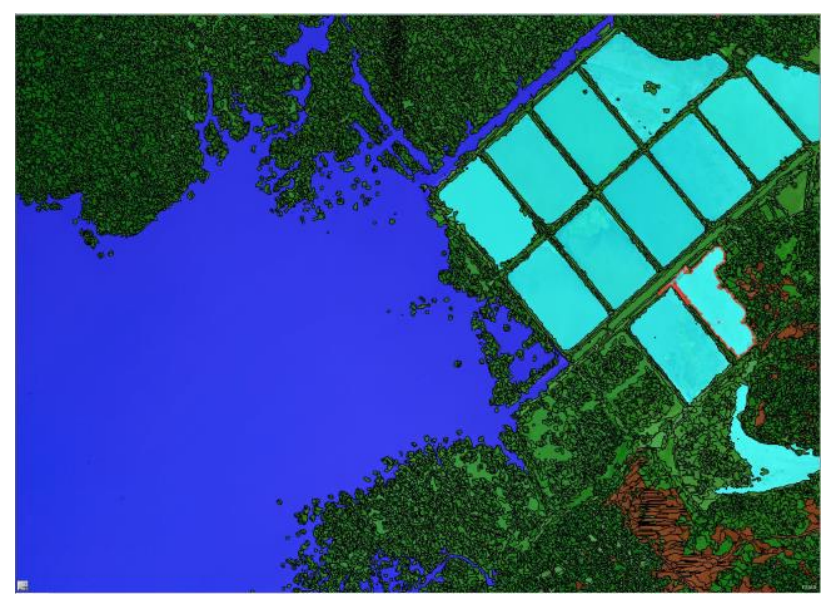

Figure 11d. Image showing extracting the aquaculture ponds.

\subsection{Aquaculture Pond Validation}

The aquaculture pond features were quite easy to identify except for those in close proximity with the rice fields. The field validation was necessary to verify aquaculture ponds from the neighbouring rice fields (see Fig. 11). Rice fields have similar characteristics with aquaculture ponds, especially those ponds in which seawater was fully or partially drained.

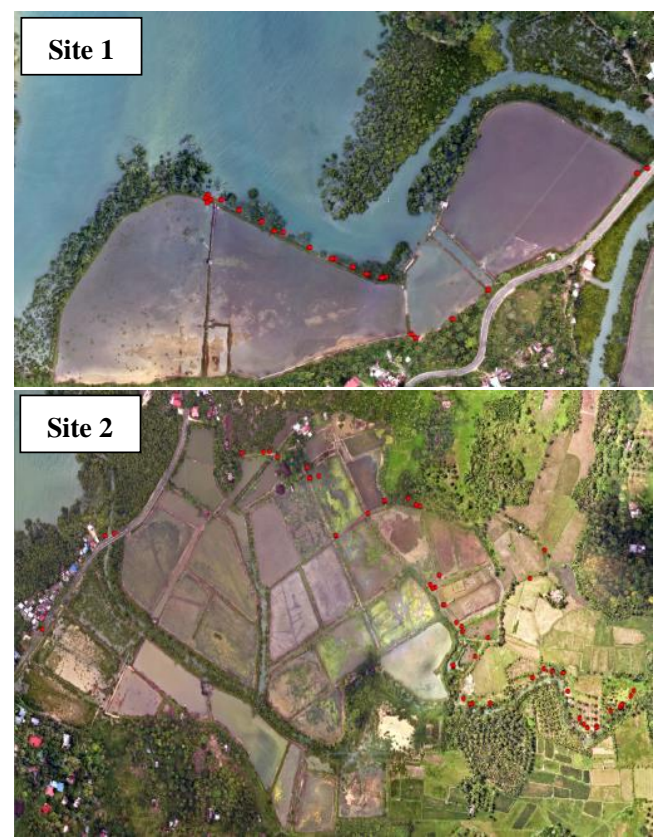

Figure 11. Validation points (red dots) overlaid on the orthophotographs.

\section{CONCLUSION}

LiDAR point cloud data was successfully utilized in the extraction of aquaculture pond features (fishponds) with minimal use of orthophotographs. The use of LiDAR derivatives in the analysis and classification of aquaculture pond feature extraction was also successfully implemented by carefully choosing their appropriate weights in the multiresolution segmentation process. The final process generated three classifications namely Water, Land and Vegetation.

\section{ACKNOWLEDGEMENTS}

We thank the Philippine Council for Industry, Energy and Emerging Technology Research and Development of the Department of Science and Technology (DOST-PCIEERD) for funding support. This paper is an output of "Project 8. LIDAR Data Processing and Validation by HEIs for Detailed Resources Assessment in the Visayas: Central Visayas (Region 7)CoastMap" under Phil-LiDAR 2. Nationwide Detailed Resources Assessment Using LiDAR Program B. LiDAR Data Processing, Modelling, and Validation for Nationwide Resources Assessment headed by Dr. Ariel Blanco. We acknowledge the research programs Phil-LiDAR 1: Hazard Mapping of the Philippines Using LiDAR and DREAM headed by Dr. Enrico Paringit for the LiDAR data. We also thank the Office of Research, University of San Carlos for logistics and financial support to the Phil-LiDAR 1 and 2 research programs. 


\section{REFERENCES}

Canny, J., 2009. A computational approach to edge detection. IEEE Transactions on Pattern Analysis and Machine Intelligence Volume 8(6) pp. 679-988.

Miliaresis, G., Kokkas, N., 2007. Segmentation and objectbased classification for the extraction of the building class from LIDAR DEMs. Computers \& Geosciences Volume 33(8), pp. 1076-1087.

Navulur, K., 2006. Multispectral image analysis using the object-oriented paradigm. New York: Taylor and Francis.

Parrish C., White S., Calder, B., Pe'eri, S., Rzhanov, Y., 2010. New Approaches for Evaluating Lidar-Derived Shoreline. Imaging and Applied Optics Congress. Tucson, AZ, USA.

Shi, Z., Wang, R., Huang, M., 2009. Detection of coastal landsat images in Shangyu City, China. Environmental Management Volume 30(1), pp. 142-150.

Terchunian, A., Klemas, V., Segovia, A., Alvarez, A., Vasconez, B., Guerrero, L., 1986. Mangrove mapping in Ecuador: The impact of shrimp pond construction Environmental Management Volume 10(3), pp. 345-350.

Travaglia, C., Profeti, G., Aguilar-Manjarrez, J., Lopez, N.A., 2004. Mapping coastal aquaculture and fisheries structures by satellite imaging radar. Case study of the Lingayen Gulf,the Philippines. FAO Fisheries Technical Paper. No. 459. Rome, FAO. $45 \mathrm{p}$. http://www.fao.org/documents/show_cdr.asp?url_file=/docrep/0 07/y5319e/y5319e00.htm.

Xie, Y., Sha, Z., Yu, M., 2008. Remote sensing imagery in vegetation mapping: a review. Journal of Plan Ecology Volume 1(1), pp. 9-23. 